\title{
Effect of Fiber Volume Fraction on Behavior of Concrete Beams Made with Recycled Concrete Aggregates
}

\author{
Wael Alnahhal, ${ }^{1, a}$ and Omar Aljidda ${ }^{2}$ \\ ${ }^{1}$ Department of Civil and Architectural Engineering, College of Engineering, Qatar University, Qatar \\ ${ }^{2}$ Department of Civil and Water Engineering, Laval University, Canada
}

\begin{abstract}
This study investigates the effect of using different volume fractions of basalt macro fibers (BMF) on the flexural behavior of concrete beams made with $100 \%$ recycled concrete aggregates (RCA) experimentally. A total of 4 reinforced concrete $(\mathrm{RC})$ beam specimens were flexural tested until failure. The parameter investigated included the BMF volume fraction $(0 \%$, $0.5 \%, 1 \%$, and $1.5 \%$ ). The testing results of the specimens were compared to control beam specimen made with no added fibers. The experimental results showed that adding BMF improves the flexural capacity of the tested beams.
\end{abstract}

\section{Introduction}

Previous studies have shown that using discrete steel fibers in concrete increases its ductility due to the large compressive strains exhibited at failure and the long-term severability [1-3]. However, among the disadvantages of using steel fibers is corrosion, especially in a harsh environment that characterizes the Arabian Gulf region, and the added weight to the concrete structure. Therefore, basalt macro-fibers were proposed in this study. Basalt fiber is a natural material that is found in volcanic basalt rocks formed in a melting temperature comprised between 1500 to $1700 \mathrm{C}$. Basalt fibers are considered to be one of the relatively new composite materials, which are characterized by their high corrosion and thermal resistance [4-6]. Basalt macro-fibers possess higher tensile strength and higher stiffness compared to conventional synthetic fibers [7]. Basalt macro-fibers modify the cracking mechanism in concrete which results in an increase in the flexural tensile strength and average residual strength, and a decrease in the crack width of the concrete [7-9]. Krassowska [10] and Brik [11] investigated the mechanical characteristics of fibers depend on their length and diameter. Based on their study, fibers with smaller diameter showed a higher tensile strength and modulus of elasticity than those fibers with a larger diameter. Jiang et al. [12] reported an improvement in the engineering properties of fiber reinforced concrete when both the volume fraction and length of fibers were increased. Bajaj [13] reported that the crack width that develops in plain concrete is larger than the crack width in polypropylene fiber concrete, which is also larger than the crack width obtained in reinforced concrete having chopped basalt fibers in the mix. Tumadhir [14] indicated that increasing the volume fraction of basalt fibers resulted in increasing the splitting tensile strength of concrete with no remarkable effect on the compressive strength of concrete. Das [15] indicated that the optimum percentage of basalt fibers in a concrete mixture is from $0.5 \%$ to $0.8 \%$ of cement's weight in order to

\footnotetext{
${ }^{a}$ Corresponding author : wael.alnahhal@qu.edu.qa
} 
achieve the best concrete properties. Dias and Thaumaturge [16] and Dong et al. [17] focused on the mechanical properties of the concrete made with RCA and basalt fibers. The results obtained from this study showed that the mechanical properties of concrete made with RCA are decreased with increasing the RCA replacement ratio. However, the mechanical properties were enhanced by using the basalt fibers. A few studies examined the flexural behavior of FRC beams. Byung and Oh [18] investigated the flexural behavior of steel FRC beams. The results indicated that the ultimate strength, ductility, and energy absorption capacity of FRC beams were considerably enhanced with the addition of steel fibers. Furthermore, the crack width was remarkably reduced as the amount of fibers increased. Similar test results were reported by Mertol et al.[19]. This work attempts to investigate the feasibility of using different volume fractions of BMF combined with $100 \%$ of RCA for structural application. Thus, this study discusses the experimental results for the flexural testing of large-scale basalt FRC beams made with $100 \%$.

\section{Experimental program}

The experimental program aimed at investigating the effect of using different volume fractions of BMF on the flexural behavior of concrete beams made with $100 \%$ recycled concrete aggregates (RCA) under four-point loading.

\subsection{Concrete mixture proportions}

The coarse aggregates used in this study were RCA with a maximum size of $20 \mathrm{~mm}$. The water/cement ratio of the mix was 0.45 . The target compressive strength of concrete was $35 \mathrm{MPa}$. As the RCA is characterized by its higher water absorption due to the attached old mortar, the amount of free water in concrete mixture plays a significant rule in the development of the hardened properties for resulting concrete. For this reason, RCA was washed and immersed in water for 24 hours before mixing, and then the surface moisture was dried with a moistened cloth, as shown in Figure1.This is to ensure that both aggregates were in a saturated surface dry condition at the time of concrete mixing. Water absorbed by saturated aggregates was not included in calculating water to cement content. This is to ensure that the remaining amount of water is approximately the same and is enough to ensure the hydration of the cement particles in the concrete mix.

BMF with an average diameter $0.72 \mathrm{~mm}$ and a length of $45 \mathrm{~mm}$ was used in this study. It is a noncorrosive discrete thin fiber made from basalt stone and coated with a solution suitable for use in concrete. It possesses higher tensile strength and stiffness, It acts as a proactive reinforcement that provides the immediate tensile load carrying capacity when micro-cracks develop in concrete. It has a tensile strength of $900 \mathrm{MPa}$ and a modulus of elasticity of $44 \mathrm{GPa}$.

\subsection{Large-scale beams flexural tests}

To study the flexural behavior of beams made with different volume fractions of BMF and with100\% of RCA, the test was carried on four large-scale beams with a size of $150 \times 250 \times 2550 \mathrm{~mm}$ that were loaded until failure under four-point loads as shown in Figure 2. Steel bars were used for as the main flexural steel reinforcement. 8-mm-diameter steel stirrups were used as transverse steel reinforcement, and two 16-mm-diameter steel bars were used as the main longitudinal bottom reinforcement. Steel stirrups were spaced as shown in Figure 3 in order to have a flexural failure at midspan of each beam. The concrete clear cover was $25 \mathrm{~mm}$. 


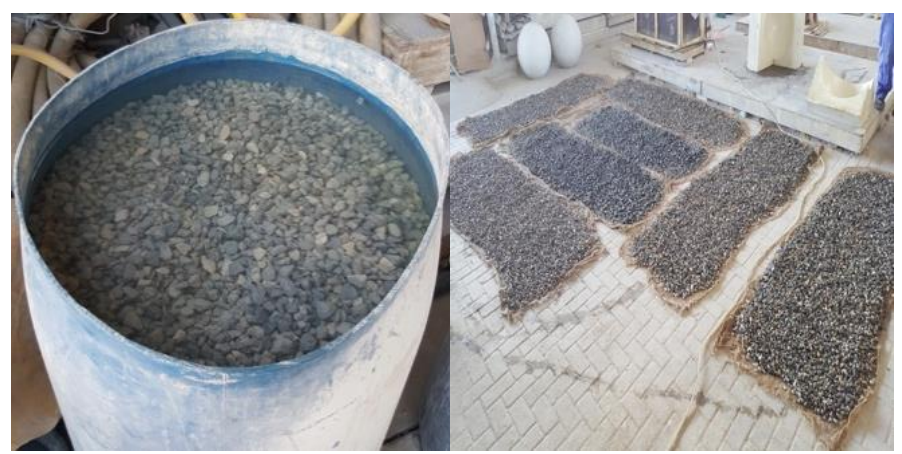

Figure 1. Moisturizing and Drying of RCA.

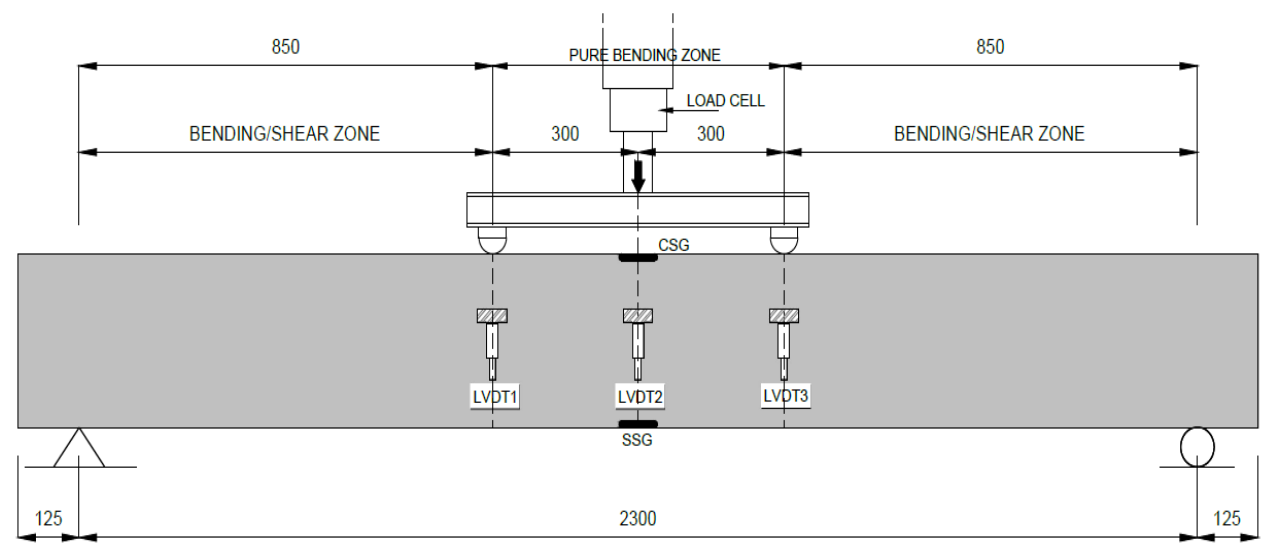

Figure 2. Large-Scale Beam Layout (Dimensions in $\mathrm{mm}$ ).

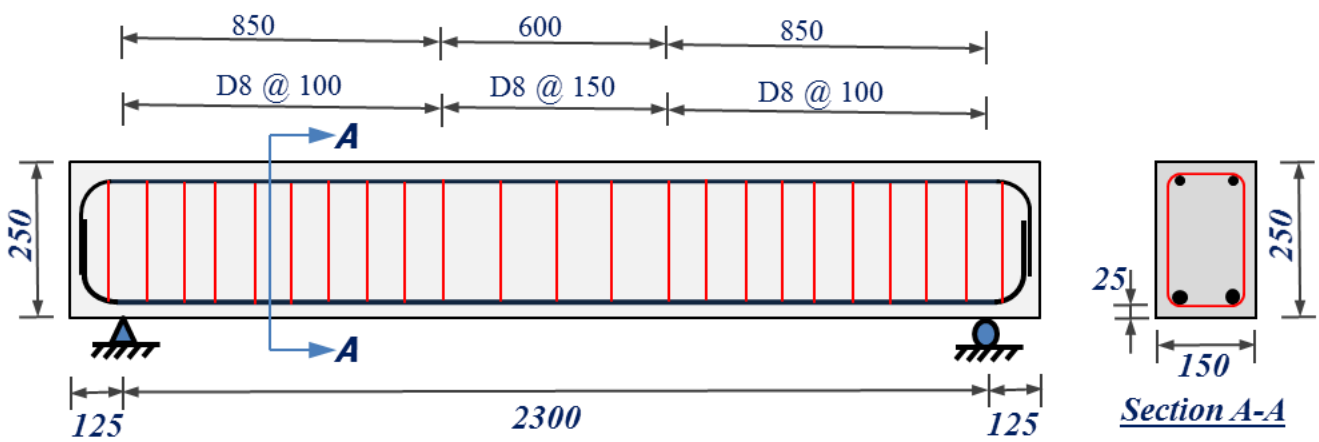

Figure 3. Beam Details and Cross Section (Dimensions in mm).

\section{Figures and tablesTests results and discussion}

All four beams specimens have $100 \%$ of RCA with $0 \%, 0.5 \%, 1 \%$, and $1.5 \%$ of BMF respectively. Flexure failure at the mid-span was the main failure mode for all four tested beams. As expected, the addition of BMF to concrete increased the maximum deflection at failure about $11.76 \%, 34.78 \%$ and $44.44 \%$ for beams with the volume fraction of $0.5 \%, 1 \%$, and $1.5 \%$ respectively compared with 
control beam as shown in Figure 4(a). The reason can be due to the effects of BMF and high bonding between BMF and concrete matrix. Figure 4(b) shows the load-concrete strain relationship where the maximum concrete strain values were $0.00292,0.00308,0.0035$ and 0.00372 for beams with $0 \%, 0.5 \%, 1 \%$ and $1.5 \%$ BMF respectively. The differences of the load-strain curves between the control beam and beams with BMF are significant. In control beam that has $0 \% \mathrm{BMF}$, once reaching the ultimate load, concrete failed by crushing and strain in reinforcement dropped suddenly. however, when the beams with BMF reached the ultimate load, concrete was held together and the strains in concrete and steel bars kept increasing gradually, this is due to the behavior of BMF, tensile loads can be transferred across the cracks by the bridging of fiber and increase in strain capacity of the concrete matrix in the pre-failure zone.

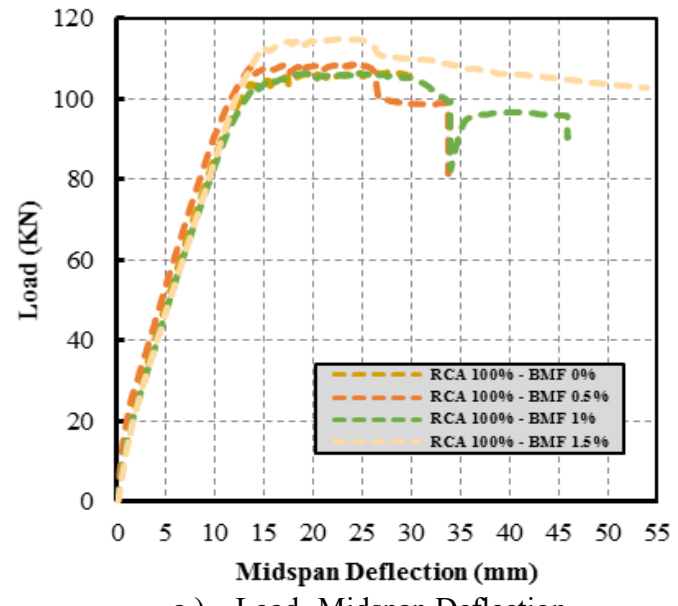

a.) Load- Midspan Deflection

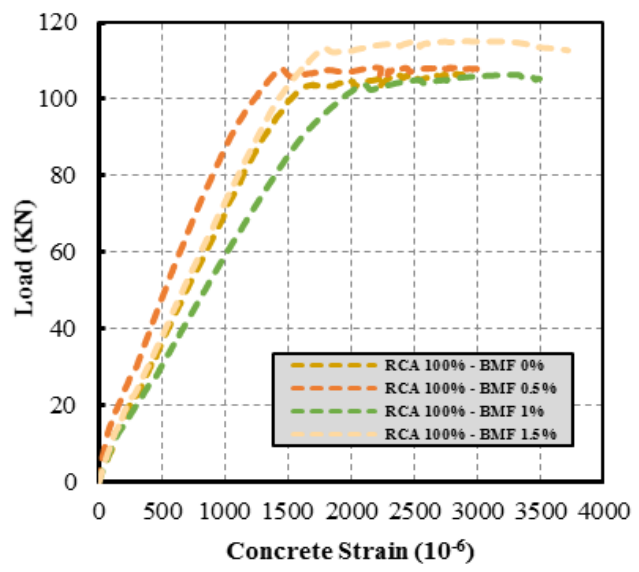

b.) Load- Concrete Strain

Figure 4. Comparison of Test Results for Beams with 100\% of RCA and different volume fraction of BMF

\section{Conclusions}

This study has investigated the mechanical properties and flexural behavior of RC beams with the different volume fraction of BMF and $100 \%$ of RCA. The following conclusions can be drawn based on the findings of the experimental investigation:

1. The addition of BMF resulted in an improvement in the ultimate flexural capacity of the tested beams compared to the beams with no BMF.

The addition of BMF resulted in an improvement in the ductility of the tested beams compared to the beams with no BMF. 


\section{Acknowledgment}

The authors show their gratitude to Qatar University for their financial support through the internal research grant QUUS-CENG-SPR14/15-21. The authors are grateful to the Construction Materials Co L.L.C. (Qatar Quarry Company) for providing the RCA.

\section{References}

1. ACI Comite 544, State of the Art Report on Fiber Reinforced Concrete Reported (ACI 544.1R-96 Reapproved 2002). ACI Structural Journal, 96(Reapproved), p.66 (2002)

2. K. Holschemacher, T. Mueller, and Y Ribakov, Effect of steel fibers on mechanical properties of high-strength concrete. Materials and Design, 31(5), pp.2604-2615 (2010)

3. J. Katzer and J. Domski, Quality and mechanical properties of engineered steel fibers used as reinforcement for concrete. Construction and Building Materials, 34, pp.243- 248 (2012)

4. A. El Refai, F. Abed, and M. Asce, Concrete Contribution to Shear Strength of Beams Reinforced with Basalt Fiber-Reinforced Bars, Journal of Composites for Construction, vol. 20, no. 4 (2016)

5. W. Alnahhal, and O. Aljidda, Flexural behavior of basalt fiber reinforced concrete beams with recycled concrete coarse aggregates. Construction and Building Materials, 169, 165-178 (2018)

6. J. Sim, C. Park, and D. Moon, Characteristics of basalt fiber as a strengthening material for concrete structures, Composites Part B: Engineering, vol. 36, pp. 504-512 (2005)

7. S. Adhikari, Mechanical and Structural Characterization of Mini-Bar Reinforced Concrete Beams. Thesis (2013)

8. P. Anil, M.Len, and A. Sudeep, Basalt Frp Minibar Reinforced Concrete, Fibre Concrete, pp. 1213 (2013)

9. P. Banibayat, and Patnaik: Variability of Mechanical Properties of Basalt Fiber Reinforced Polymer Bars Manufactured By Wet-Layup Method. Materials and Design, 56, pp.898-906. (2014)

10. J. Krassowska and A. Lapko, The Influence of Steel and Basalt Fibers on the Shear and Flexural Capacity of Reinforced Concrete Beams. Journal of Civil Engineering and Architecture. vol. 7, no. 7, pp. 789-795 (2013)

11. V. Brik, Basalt Fiber Composite Reinforcement for Concrete, Transportation Research Board National Research Council, Madison, Wisconsin (1997)

12. C. Jiang, K. Fan, F. Wu, and D. Chen, Experimental study on the mechanical properties and microstructure of chopped basalt fibre reinforced concrete: Mater. Des., vol. 58, pp. 187-193, (2014)

13. S. Bajaj, Effect of Corrosion on Physical and Mechanical Properties of Reinforced Concrete. Ph.D. Thesis (2012)

14. M. Tumadhir, Thermal and Mechanical Properties of Basalt Fiber Reinforced Concrete, World Academy of Science, Engineering and Technology, vol. 7, no. 4, pp. 712-715 (2013)

15. W. Das, The impact of basaltic fibre on selected physical and mechanical properties of cement mortar. Concert Precast. Plant Technology, vol. 71, no. 3, pp. 28-33 (2005)

16. D. Dias and C. Thaumaturgo, Fracture toughness of geopolymeric concretes reinforced with basalt fibers: Cement and Concrete Compost, vol. 27, no. 1, pp. 49-54 (2005)

17. J. Dong, Q. Wang, and Z. Guan, Material properties of basalt fibre reinforced concrete made with recycled earthquake waste, Construction and Building Material, vol. 130, pp. 241-251 (2017)

18. B. Byung and H. Oh: Flexural Analysis of Reinforced Concrete Beams Containing Steel Fibers, Journal of structural engineering, vol. 118, issue 10, pp. 2821-2835 (1992)

19. H. Mertol, E. Baran, and H. Bello, Flexural behavior of lightly and heavily reinforced steel fiber concrete beams, Construction and Building Material, vol. 98, pp. 185-193 (2015) 